\title{
Prevalence and associated factors related to arm, neck and shoulder complaints in a selected sample of computer office workers
}

\author{
Original \\ Article \\ Noha S. Elshaer \\ Community Medicine Department, Faculty of Medicine, Alexandria University, Alexandria, \\ Egypt
}

\begin{abstract}
Background: Globally, there is an expansion in computer-related work, which may have contributed to an increased burden of complaints of the arm, neck and/or shoulder (CANS). The study was conducted to determine the prevalence and factors associated with CANS among computer office workers (OWs) in Alexandria.

Participants and Methods: Computer OWs at four banks and two telecommunication companies ( $\mathrm{n}=211)$ were included in a cross-sectional study in 2016. Data were collected using the self-administered Musculoskeletal Upper Extremity Questionnaire-Arabic version. Potentially related factors were examined using bivariate and multivariate analyses.

Results: The sample comprised 95 (45.02\%) males and 116 (54.97\%) females. Overall, 72\% aged 25-35 years. Prevalence with 95\% confidence interval (CI) for CANS was 0.73 (95\% CI: 0.66-0.79), 0.69 (95\% CI: 0.62-0.75) and 0.70 (95\% CI: $0.64-0.76)$, respectively. The majority of the complaints were minor (86\%). Factors significantly associated with neck complaints were female sex $(\mathrm{P}=0.03)$, inappropriate office equipment $(\mathrm{P}=0.02)$, task complexity $(\mathrm{P}<0.01)$, break autonomy $(\mathrm{P}=0.02)$ and low decision authority $(\mathrm{P}=0.05)$. Factors significantly associated with arm/hand complaints were female sex $(\mathrm{P}=0.01)$, awkward body posture $(\mathrm{P}=0.05)$, break autonomy $(\mathrm{P}<0.01)$ and low break quality $(\mathrm{P}=0.04)$

Conclusion: The study revealed high prevalence of CANS and highlighted associated factors, namely, task complexity, inappropriate office equipment, low decision authority, low break quality and female sex. Improving ergonomic conditions, reducing job demands, and increasing job control are crucial to reduce CANS among computer OWs.
\end{abstract}

Received: 27 July 2017, Accepted: 20 October 2017

Key Words: Complaints, factors, neck, prevalence, workers

Corresponding Author: Noha S. Elshaer, MD, Community Medicine Department, Faculty of Medicine, Alexandria University, Champilion Street, El Azareeta, Alexandria 21131, Egypt, Tel.: +20 1005641972, E-mail: noha.alshaaer@alexmed.edu.eg, elshaer.n@gmail.com

Journal of the Egyptian Public Health Association, ISSN: 0013-2446, Vol. 92, No.4

\section{INTRODUCTION}

Complaints of arm, neck and/or shoulder (CANS) are defined as musculoskeletal complaints of arm, neck, and/ or shoulder not caused by acute trauma or by any systemic disease $[1,2]$. A computer office worker $(\mathrm{OW})$ is a person whose job tasks include typing or filing documents, correspondence, reports, statements and other materials; most of the tasks involve using a computer [3]. In office, workstation is usually equipped with chair, table, computer, telephone and other equipment [4]. Computer OW is one of the occupations that can potentially be affected by CANS $[5,6]$.

Globally, there is an expansion in computer-related work [5], which may have contributed to an increased burden of CANS [7]. Workers may experience severe debilitating symptoms such as pain, numbness and tingling [8]. CANS were recognized about three decades back as a major cause of work-related inefficiency [9], absenteeism, lower level of performance and productivity, poor quality of life and rising medical costs [10]. In developing countries, workers' suffering would be great, as only $5-10 \%$ of workers have access to occupational health services [11].
Prevalence of CANS among computer OWs varies in studies. Some studies reported low prevalence $(28,31$, and $35.8 \%)[2,12,13]$. On the contrary, a relatively higher prevalence was reported in other studies $(45,53,53.6,54$, and 56.9\%) $[3,5,7,8,9]$. The highest percentage of CANS was reported in the neck region followed by shoulder $[5,9,14]$; however, the opposite has also been reported [13].

Many factors were reported to cause CANS [13]; however, varying results were found in several studies. Poor ergonomic conditions at workstations such as inappropriate workplace design $[8,13,15-18]$, static and/or irregular body postures and repetitive tasks were reported to cause CANS $[13,18]$. Moreover, psychosocial factors, such as high quantitative and/or qualitative job demands, low job control and limited social and coworker support were significantly related to CANS $[13,19,20]$. In addition, increase in the number of working hours/day, inability to use break after work with computer and lack of awareness about computer ergonomics were significantly associated with development of CANS $[3,8,12,13]$.

Employment of computer and information technology occupations are projected to grow faster than the average 
for all occupations from 2014 to 2024 [21]. Therefore, defining an etiological model that prioritizes modifiable factors is crucial to design evidence-based preventive strategies aiming at reducing CANS in the following years [3].

Studies showed varied results regarding prevalence and risk factors for CANS. Most of the studies were conducted in Europe and Asia [3,7,8,12,13,15], whereas limited data are available about Africa [5,22]. The present study was conducted to determine the prevalence and factors associated with CANS among working population. The specific objectives of the study were as follows: (a) to determine the prevalence rate of CANS in a selected sample of computer OWs; (b) to describe the nature, severity and distribution of CANS by anatomical localization; and (c) to identify factors associated with CANS.

\section{PARTICIPANTS AND METHODS}

\section{Study design and Sampling}

A cross-sectional approach was used from the beginning of September 2016 to the end of December 2016 on a convenient sample comprising four banks and two telecommunication companies in Alexandria. All registered computer OWs $(\mathrm{n}=258)$ were invited to participate. Workers were excluded if they had duration of employment of less than 6 months. All participants performed computer tasks at their work, such as typing, filing documents, data entry and other administrative tasks. The response rate was $81.78 \%$.

\section{Study tool}

The Musculoskeletal Upper Extremity Questionnaire (MUEQ) [3,7], a validated screening tool, was used to assess occurrence of CANS and work-related physical and psychosocial factors. Psychosocial factors measured in MUEQ are derived from Job Demand-Control-Model, which assumes that psychological strain results from a joint effect of level of job demands and job control $[23,24]$.

The self-administered MUEQ-Arabic version was distributed among OWs by handing them out at their workplace. Workers were asked to fill out and return the questionnaires within 2 weeks. The returned questionnaires were checked for completeness.

\section{Musculoskeletal Upper Extremity Questionnaire- Arabic version}

It comprised 107 items derived from MUEQ-Dutch version that was developed in 1999, and it was found to be valid and reliable [7]. It has been translated to Arabic language, validated for the Arab population; it showed satisfactorily psychometric properties to be used among Arabian Computer OWs [5].

MUEQ was used to collect data about the following: (a) characteristics of the study population, including age, sex, number of working hours with computer/day and number of working years in the current position; (b) prevalence of CANS: the outcome variable was presence of complaint (yes/no) for each body region (neck, shoulder and arm/ hand) lasting for at least 1 week over the past 12 months, where cases with pain complaint were classified as severe cases if pain persists even after a short rest period; (c) six main scales of MUEQ to assess work-related physical and psychosocial factors, including work station (six items), body posture (10 items), break time (nine items), job control (nine items), job demands (six items) and social support (12 items); (d) frequency and nature of complaints; and (e) Clinical manifestations, for example, continuous pain, tingling, numbness, stiffness, fatigue, and change in skin color. Items were scored on either yes/ no dichotomous scale or a five-point scale (always-oftensometimes-seldom-rare). A Cronbach's $\alpha$ and values of item-total correlations were calculated for each scale in MUEQ-Arabic version [5].

Each item of all scales (except work station scale) was scored on a five-point scale (always-often-sometimesseldom-rare representing 5-4-3-2-1, respectively); however, in certain items where the sentence was negatively phrased, a reverse score was considered (1-2-3-4-5, respectively). Regarding workstation scale, each item of its two subscales was scored on a (yes-no) dichotomous scale ( $0-2$, respectively) to enter the logistic regression model as 'inappropriate office equipment' and inappropriate computer position'.

The scales for assessing the work-related physical and psychosocial factors

The workstation scale included two subscales. The first subscale determines worker's perception of office equipment (four items, range: 0-8 points). Participants were asked about desk position, using chair that supports lower back, using document keeper to fix documents during printing, and having enough space to work on the desk. The second subscale determines computer position (two items, range: 0-4). Participants were asked about keyboard position, and sitting in a straight horizontal position in front of the screen.

The body posture scale included two subscales. The first subscale determines head and body posture (six items, range: 6-30). Participants were asked about having physically exhausting job, placing hand in a straight line with lower arm during keying, head position (bended or twisted towards the left or right side), and trunk position (asymmetrical position, or twisted towards the left or right side). The second subscale determines awkward body posture (four items, range: 4-20). Participants were asked about sitting for long hours in one position, sitting with lifted shoulders for more than $2 \mathrm{~h}$ per day, awkward posture, and repetitive tasks (printing).

The break time scale included two subscales. The first subscale determines break autonomy (four items, range: 4-20). Participants were asked about 
the ability to decide when to take a break, when to start and finish tasks, divide tasks, and sufficiency of break time. The second subscale determines break quality (five items, range: 5-25). Participants were asked about changing body posture, changing tasks, performing certain tasks without computer, taking a 10-min break every $2 \mathrm{~h}$, and spending break time outside office.

The job control scale included two subscales. The first subscale determines skills discretion (six items, range: 6-30). Participants were asked about developing abilities, creativity, learning new things and decision making at work. The second subscale determines decision authority (three items, range: 3-15). Participants were asked about the ability to decide how to perform job task and to solve work problems by themselves.

The job demand scale included two subscales. The first subscale determines time pressure (three items, range: 3-15). Participants were asked about difficulty to finish tasks on time and taking extra working hours. The second subscale determines task complexity (three items, range: 3-15). Participants were asked about working pressure, difficult tasks, and speeding at work to finish tasks.

The social support scale included two subscales. The first subscale determines relationship among coworkers and between workers and supervisors (seven items, range: 7-35). Participants were asked about supervisor's support, positive evaluation from colleagues, and emotional support for personal issues. The second subscale determines work flow (five items, range: 5-25). Participants were asked about work flow, ability to ask and enquire, depending on colleagues to perform tasks and comfortable work atmosphere.

\section{Statistical analysis}

Data were analyzed using Stata statistical software, version 14 (Stata Corp LP, College Station, Texas, USA). Frequency, percentages, mean, and SD were calculated to describe the study population. Prevalence of complaints was calculated including 95\% confidence interval (CI) for each body region and in combinations of regions. Percentages of complaints with respect to anatomical localization (right side, left side, or both) were demonstrated.

Association between each potential factor and outcome variable was examined separately for neck, shoulder and arm/hand complaints using bivariate analysis. In addition, multivariate analysis using logistic regression was performed including all potential factors to determine the factors significantly associated with CANS. Associations were considered statistically significant if $\mathrm{P}$ up to 0.05 . The explained variance of logistic regression model was calculated by means of Nagelkerke's R2 and the goodness of fit by means of the Hosmer and Lemeshow goodness-of fit test.

\section{Ethical considerations}

The study was approved by the Research Ethics Committee at the Alexandria Faculty of Medicine. Objectives, procedures, types of information to be obtained and the expected benefits of publication of results were explained to participants. An informed consent was obtained from each participant. Collected data were confidentially kept.

\section{RESULTS}

The study population $(\mathrm{n}=211$; response rate $=81.78 \%)$ comprised $95(45 \%)$ males and $116(54.9 \%)$ females. Overall, $28 \%$ of the study population had number of working hours/day of more than $8 \mathrm{~h}$ and $55.9 \%$ have been working in the current position for more than 4 years. More than half of participants worked with computer for $6-8 \mathrm{~h} /$ day $(54.5 \%)$ (Table 1$)$. The mean duration of employment and mean computer working hours/day were significantly higher among males $(9.67 \pm 7.85$ years and $7.81 \pm 2.61 \mathrm{~h})$ compared with females $(6.99 \pm 6.00$ years and $5.97 \pm 2.12$ $\mathrm{h}$, respectively) $(\mathrm{t}=2.80, \mathrm{P}<0.01 ;$ and $\mathrm{t}=5.61, \mathrm{P}<0.01$ respectively) (data not shown).

\section{Prevalence of complaints of the arm, neck and/or shoulder}

The prevalence of neck complaints was $0.69(95 \%$ CI: $0.62-0.75)$, shoulder 0.70 (95\% CI: 0.64-0.76), and arm/hand 0.73 (95\% CI: 0.66-0.79) (Table 2). The prevalence of CANS was significantly higher among females $(0.76,0.76$ and 0.81 , respectively) compared with males $(0.60,0.63$ and 0.63 , respectively) $(\mathrm{P}<0.01,0.03$ and 0.01 , respectively).

Overall, $54 \%$ of the study population reported symptoms of whole upper musculoskeletal extremity. The prevalence of severe cases was 0.14 (95\% CI: 0.08-0.19), of whom $57.89 \%$ were females (Table 2). In general, right side complaints were more frequently reported than left side (Table 3).

\section{Factors associated with neck complaints}

In multivariate analysis, factors significantly associated with neck complaints were female sex [odds ratio (OR) 2.4; 95\% CI: 1.09-5.39; $\mathrm{P}=0.03$ ], appropriateness of the office equipment (OR 6.4; 95\% CI: 1.31-31.4; $\mathrm{P}=0.02$ ), task complexity (OR 16.9; 95\% CI: 3.2-89.15, $\mathrm{P}<0.01$ ), decision authority (OR 0.1; 95\% CI: $0.02-1.06 ; \mathrm{P}=0.05$ ), break autonomy (OR 2.6; 95\% CI: 1.13-5.97; $\mathrm{P}=0.02$ ) and working years in the current position (OR 1.0; 95\% CI: $1.00-1.13 ; \mathrm{P}=0.02)$. The logistic regression model was significant $(\chi 2=49.12, \mathrm{P}<0.01)$. The Nagelkerke's $\mathrm{R} 2$ was 0.31 , and the Hosmer-Lemeshow goodness-of-fit test was not significant $(\chi 2=14.44, \mathrm{P}=0.07)$ (Table 4).

\section{Factors associated with shoulder complaints}

Results of bivariate analyses indicated a significant 
association between shoulder complaints and sex (OR 1.9; 95\% CI: 1.05-3.50; $\mathrm{P}=0.03$ ), time pressure (OR 2.7, 95\% CI: 1.46-5.10; $\mathrm{P}<0.01$ ), and task complexity (OR 2.6; 95\% CI: 0.98-6.9; $\mathrm{P}=0.05$ ). However, the logistic regression model was not significant $(\chi 2=24.24, \mathrm{P}=0.06)$ (data not shown).

\section{Factors associated with $\mathrm{arm} / \mathrm{hand}$ complaints}

In multivariate analysis, factors significantly associated with arm/hand complaints were female sex
(OR 2.8; 95\% CI: 1.21-6.69; $\mathrm{P}=0.01$ ), awkward body posture (OR 6.2; 95\% CI: 0.98-39.22; $\mathrm{P}=0.05$ ), break autonomy (OR 3.2; 95\% CI: 1.34-7.94; $\mathrm{P}<0.01$ ), break quality (OR $0.1,95 \%$ CI: $0.01-0.94 ; \mathrm{P}=0.04$ ) and duration of employment in the current position (OR 1.1; $95 \% \mathrm{CI}$ : $1.00-1.12 ; \mathrm{P}=0.03)$. The logistic regression model was significant $(\chi 2=50.70, \mathrm{P}<0.01)$. The Nagelkerke's $\mathrm{R} 2$ was 0.33 , and the Hosmer-Lemeshow goodness-of-fit test was not significant $(\chi 2=4.83, \mathrm{P}=0.77)$ (Table 5).

Table 1 Characteristics of the sample of computer office workers, Alexandria, Egypt, 2016

\begin{tabular}{|c|c|c|c|}
\hline Characteristics & Total $(\mathrm{n}=211)[\mathrm{n}(\%)]$ & Male (n=95) [n (\%)] & Female $(n=116)$ \\
\hline \multicolumn{4}{|l|}{ Age (years) ${ }^{\mathrm{a}}$} \\
\hline $25-35$ & $153(72.5)$ & $60(63.2)$ & $93(80.2)$ \\
\hline $36-45$ & $39(18.5)$ & $23(24.2)$ & $16(13.8)$ \\
\hline$>45$ & $19(9.0)$ & $12(12.6)$ & $7(6.0)$ \\
\hline \multicolumn{4}{|c|}{ Number of working (h/day) } \\
\hline $4-7$ & $94(44.5)$ & $20(21.1)$ & $74(63.8)$ \\
\hline 8 & $58(27.5)$ & $29(30.5)$ & $29(25.0)$ \\
\hline$>8$ & $59(28.0)$ & $46(48.4)$ & $13(11.2)$ \\
\hline Mean \pm SD & $8.2 \pm 2.7$ & $9.6 \pm 3.1$ & $7.0 \pm 1.5$ \\
\hline \multicolumn{4}{|c|}{ Number of working hours with computer/day } \\
\hline$<3$ & $8(3.8)$ & $0(0.00)$ & $8(6.9)$ \\
\hline $3-5$ & $51(24.2)$ & $17(17.9)$ & $34(29.3)$ \\
\hline $6-8$ & $115(54.5)$ & $54(56.8)$ & $61(52.6)$ \\
\hline$>8$ & $37(17.5)$ & $24(25.3)$ & $13(11.2)$ \\
\hline Mean \pm SD & $6.8 \pm 2.5$ & $7.8 \pm 2.6$ & $5.9 \pm 2.1$ \\
\hline \multicolumn{4}{|c|}{ Duration of employment in current position (years) } \\
\hline $2-4$ & $93(44.1)$ & $33(34.7)$ & $60(51.7)$ \\
\hline$>4$ & $118(55.9)$ & $62(65.3)$ & $56(48.3)$ \\
\hline Mean \pm SD & $8.2 \pm 7.0$ & $9.6 \pm 7.8$ & $6.9 \pm 6.0$ \\
\hline
\end{tabular}

aIn MUEQ-Arabic version questionnaire, age is a categorical variable; the question to obtain data on age had three choices (the exact age of the participant was not written in the questionnaire). So it would not be possible to calculate mean and SD for age variable. 
Table 2 Prevalence rate of complaints of the arm, neck and/or shoulder lasting for at least 1 week during the previous 12 months among computer OWs, Alexandria, Egypt, 2016

\begin{tabular}{|c|c|c|c|c|}
\hline \multirow[b]{2}{*}{ Complaints } & \multirow[b]{2}{*}{$\mathbf{N}$} & \multicolumn{3}{|c|}{ Prevalence (95\% CI) } \\
\hline & & Total $(\mathrm{n}=\mathbf{2 1 1})$ & Male (n=95) & Female $(n=116)$ \\
\hline \multicolumn{5}{|l|}{ Body region } \\
\hline Neck & 146 & $0.69(0.62-0.75)$ & $0.60(0.49-0.70) \mathrm{a}$ & $0.76(0.68-0.84)^{a}$ \\
\hline Shoulder & 149 & $0.70(0.64-0.76)$ & $0.63(0.53-0.73) \mathrm{a}$ & $0.76(0.68-0.84)^{\mathrm{a}}$ \\
\hline Arm $/$ hand $^{b}$ & 154 & $0.73(0.66-0.79)$ & $0.63(0.53-0.73) \mathrm{a}$ & $0.81(0.73-0.88)^{\mathrm{a}}$ \\
\hline \multicolumn{5}{|l|}{ Complaints in combined body regions } \\
\hline Neck and shoulder symptoms & 9 & $0.04(0.01-0.07)$ & $0.06(0.01-0.11)$ & $0.02(0.00-0.05)$ \\
\hline Neck and arm/handb symptoms & 13 & $0.06(0.02-0.09)$ & $0.07(0.02-0.12)$ & $0.05(0.01-0.09)$ \\
\hline Shoulder and arm/handb symptoms & 21 & $0.10(0.05-0.14)$ & $0.10(0.04-0.16)$ & $0.09(0.04-0.14)$ \\
\hline Neck, shoulder and arm/handb symptoms & 114 & $0.54(0.47-0.60)$ & $0.42(0.31-0.52)$ & $0.63(0.54-0.72)$ \\
\hline \multicolumn{5}{|l|}{ Severity of pain among cases ${ }^{\mathrm{c}}$} \\
\hline & & $\mathrm{n}=136$ & $\mathrm{n}=52$ & $\mathrm{n}=84$ \\
\hline Mild cases $^{\mathrm{d}}$ & 117 & $0.86(0.80-0.91)$ & $0.84(0.74-0.94)$ & $0.86(0.79-0.94)$ \\
\hline Sever cases ${ }^{\mathrm{e}}$ & 19 & $0.14(0.08-0.19)$ & $0.15(0.05-0.25)$ & $0.13(0.05-0.20)$ \\
\hline
\end{tabular}

CANS, complaints of arm, neck and shoulder; CI, confidence interval; OWs, office workers.

${ }^{a}$ The prevalence of CANS was significantly higher among females $(0.81,0.76,0.76$, and 0.81 , respectively) compared with males $(0.63,0.60$, and 0.63 , respectively) $(\mathrm{P}<0.01, \mathrm{P}=0.03$ and $\mathrm{P}<0.01$, respectively).

${ }^{b}$ Upper arm, elbow, lower arm, wrist, or hand complaints.

${ }^{\mathrm{c}}$ Cases with pain in the upper musculoskeletal extremity.

${ }^{\mathrm{d}}$ Pain disappears after short period of rest.

ePain persists even after short period of rest.

Table 3 Frequency of complaints in upper musculoskeletal extremity distributed by anatomical localization and sex among computer office workers, Alexandria, Egypt, 2016

\begin{tabular}{|c|c|c|c|c|c|c|}
\hline \multirow[b]{2}{*}{ Sex and body side } & \multicolumn{6}{|c|}{ Anatomical localization } \\
\hline & Shoulder & Upper arm & Elbow & Lower arm & Wrist & Hand \\
\hline All (n) & 149 & 123 & 91 & 88 & 91 & 104 \\
\hline Right side & 36.2 & 41.5 & 46.1 & 46.6 & 46.2 & 52 \\
\hline Left side & 10.1 & 8.9 & 4.4 & 1.1 & 3.3 & 3.8 \\
\hline Both sides & 53.7 & 49.6 & 49.5 & 52.3 & 50.5 & 44.2 \\
\hline Male (n) & 60 & 46 & 35 & 27 & 31 & 38 \\
\hline Right side & 40 & 45.7 & 48.6 & 55.6 & 41.9 & 52.6 \\
\hline Left side & 15 & 15.2 & 5.7 & 0.00 & 6.5 & 5.3 \\
\hline Both sides & 45 & 39.1 & 45.7 & 44.4 & 51.6 & 42.1 \\
\hline Female (n) & 89 & 77 & 56 & 61 & 60 & 66 \\
\hline Right side & 33.7 & 39 & 44.6 & 41 & 48.3 & 51.5 \\
\hline Left side & 6.7 & 5.2 & 5.4 & 1.6 & 1.7 & 3 \\
\hline Both sides & 59.6 & 55.8 & 50 & 57.4 & 50 & 45.5 \\
\hline
\end{tabular}

${ }^{\mathrm{a}}$ Complaints lasting for at least 1 week during the previous 12 months. 
Table 4 Factors associated with neck complaints

\begin{tabular}{|c|c|c|c|c|}
\hline \multirow[b]{2}{*}{ Risk factors } & \multicolumn{2}{|c|}{ Bivariate analysis } & \multicolumn{2}{|c|}{ Multivariate analysis ${ }^{\mathrm{a}}$} \\
\hline & ORb $(95 \%$ CI) & P-value & Adjusted $\mathrm{OR}^{\mathrm{b}}(95 \% \mathrm{CI})$ & P-value \\
\hline Sex (female) ${ }^{c}$ & $2.1(1.21-3.98)$ & $<0.01$ & $2.4(1.09-5.39)$ & 0.03 \\
\hline Working years in current position & $1.0(0.98-1.08)$ & 0.14 & $1.0(1.00-1.13)$ & 0.02 \\
\hline Computer working (h/day) & $1.0(0.90-1.13)$ & 0.84 & $1.0(0.90-1.23)$ & 0.50 \\
\hline Inappropriate office equipment & $4.3(1.25-14.8)$ & 0.02 & $6.4(1.31-31.4)$ & 0.02 \\
\hline Inappropriate computer position & $1.6(0.45-6.25)$ & 0.78 & $0.5(0.10-3.25)$ & 0.53 \\
\hline Irregular head and body posture & $0.9(0.38-2.51)$ & 0.97 & $0.4(0.09-2.10)$ & 0.30 \\
\hline Awkward body posture & $2.3(0.55-9.54)$ & 0.24 & $1.4(0.24-9.28)$ & 0.66 \\
\hline Break autonomy & $1.9(1.05-3.65)$ & 0.03 & $2.6(1.13-5.97)$ & 0.02 \\
\hline Break quality & $2.4(0.91-6.46)$ & 0.07 & $1.6(0.45-6.06)$ & 0.44 \\
\hline Skills discretion & $0.7(0.32-1.54)$ & 0.38 & $2.1(0.3-12.07)$ & 0.36 \\
\hline Decision authority & $0.3(0.13-1.00)$ & 0.05 & $0.1(0.02-1.06)$ & 0.05 \\
\hline Time pressure & $2.5(1.36-4.70)$ & $<0.01$ & $1.2(0.50-2.95)$ & 0.65 \\
\hline Task complexity & $9.6(3.04-30.7)$ & $<0.01$ & $16.9(3.2-89.1)$ & $<0.01$ \\
\hline Social support & $0.5(0.18-1.81)$ & 0.34 & $0.9(0.17-4.99)$ & 0.94 \\
\hline Work flow & $0.3(0.07-1.49)$ & 0.15 & $0.7(0.11-5.69)$ & 0.82 \\
\hline Model $\chi 2=49.12(<0.01)$ & & & & \\
\hline
\end{tabular}

CI, confidence interval; OR, odds ratio.

${ }^{\mathrm{a} M u l t i v a r i a t e}$ analysis using logistic regression.

'Odds ratios. The Nagelkerke's R2 $=0.31$ and the Hosmer-Lemeshow goodness-of-fit test was not significant $(\chi 2=14.44, \mathrm{P}=0.07)$.

'Reference is male.

Table 5 Factors associated with arm/hand ${ }^{\mathrm{a}}$ complaints

\begin{tabular}{|c|c|c|c|c|}
\hline \multirow[b]{2}{*}{ Risk factors } & \multicolumn{2}{|c|}{ Bivariate analysis } & \multicolumn{2}{|c|}{ Multivariate analysis $^{\mathrm{b}}$} \\
\hline & ORc $(95 \% \mathrm{CI})$ & P-value & Adjusted OR $(95 \%$ CI) & P-value \\
\hline Sex $(\text { female })^{b}$ & $2.4(1.33-4.65)$ & $<0.01$ & $2.8(1.21-6.69)$ & 0.01 \\
\hline Working years in the current position & $1.03(0.9-1.09)$ & 0.11 & $1.1(1.00-1.12)$ & 0.03 \\
\hline Computer working (h/day) & $0.9(0.85-1.08)$ & 0.57 & $0.9(0.85-1.16)$ & 0.99 \\
\hline Inappropriate office equipment & $0.9(0.38-2.22)$ & 0.85 & $0.8(0.26-2.93)$ & 0.83 \\
\hline Inappropriate computer position & $2.3(0.50-10.7)$ & 0.28 & $1.8(0.27-12.9)$ & 0.51 \\
\hline Irregular head and body posture & $2.3(0.98-5.82)$ & 0.05 & $1.7(0.47-6.56)$ & 0.39 \\
\hline Awkward body posture & $8.8(1.73-45.4)$ & $<0.01$ & $6.2(0.9-39.22)$ & 0.05 \\
\hline Break autonomy & $1.7(0.91-3.29)$ & 0.09 & $3.2(1.34-7.94)$ & $<0.01$ \\
\hline Break quality & $0.5(0.14-1.84)$ & 0.30 & $0.1(0.01-0.94)$ & 0.04 \\
\hline Skills discretion & $0.1(0.51-0.59)$ & $<0.01$ & $0.8(0.10-6.56)$ & 0.86 \\
\hline Decision authority & $0.1(0.00-0.53)$ & 0.01 & $0.1(0.00-1.79)$ & 0.11 \\
\hline Time pressure & $3.7(1.97-7.12)$ & $<0.01$ & $1.8(0.73-4.41)$ & 0.19 \\
\hline Task complexity & $3.8(1.43-10.3)$ & $<0.01$ & $2.9(0.7-12.00)$ & 0.14 \\
\hline Social support & $0.2(0.06-1.29)$ & 0.10 & $0.5(0.06-3.90)$ & 0.52 \\
\hline Work flow & $0.3(0.08-1.82)$ & 0.23 & $0.9(0.11-7.37)$ & 0.95 \\
\hline Model $\chi 2=50.70(<0.01)$ & & & & \\
\hline
\end{tabular}

The Nagelkerke's R2=0.33, and the Hosmer-Lemeshow goodness-of-fit test was not significant $(\chi 2=4.83, \mathrm{P}=0.77)$.

CI, confidence interval; OR, odds ratio.

aUpper arm, elbow, lower arm, wrist, or hand complaints.

${ }^{\mathrm{b}}$ Reference is male.

${ }^{\mathrm{b}}$ Multivariate analysis using logistic regression.

${ }^{\mathrm{c}}$ Odds ratios. 


\section{DISCUSSION}

By 2020, employment in all computer occupations is expected to increase by $22 \%$ [21]. Therefore, identifying potential risk factors for CANS would be essential to design preventive strategies [3]. The current study reported high prevalence of CANS among computer OWs compared with other studies $[2,12,13]$, even those conducted in comparable developing countries [5,25-27]. Moreover, in the present study, the prevalence of neck complaints was similar to shoulder complaints and slightly lower than arm/hand complaints. However, some studies reported neck complaints higher than shoulder complaints $[5,9,14]$, and both were much higher than arm/hand complaints $[5,13,28]$. Studies indicate that globally, CANS are not typical and are multifactorial with possible interactions between different factors.

In the present study, although the mean duration of employment and computer working/day were significantly higher among males compared with females, yet the prevalence of CANS among females was significantly higher than males. In multivariate analysis, female sex was significantly associated with neck and arm/hand complaints. A female computer OW was 2.4 times more likely to have neck complaints and 2.8 times more likely to have arm/hand complaints compared with a male computer OW. Findings of the present study are in total agreement with the results of several studies where the reported upper musculoskeletal complaints among females were significantly higher than males $[3,5,13,18,26]$. Hooftman et al. [29] mentioned that sex difference might be explained by differences in exposures to work-related factors. Another possible explanation could be vulnerability of females, which makes them more likely than males to have complaints when they are exposed to same work-related factors.

In the current study, most participants were classified as mild cases (severe case were $14 \%$, and mild cases were $86 \%$ ). This is in line with the study by Eltayeb et al. [5], where only $4 \%$ of respondents were classified as severe cases. Moreover, in the study by Kryger et al. [30], only 16 of 296 participants with forearm pain were clinically diagnosed as a forearm case. Furthermore, in the study by Andersen et al. [18], less than 3\% of participants reported moderate to severe neck pain. Subjective assessment of severity of pain in the current study might be the reason for the relatively higher severity rate (14\%) compared with the results of other studies. Eltayeb et al. [5] mentioned that it would be better to describe the condition as fluctuating daily aches and pain instead of being a health problem that necessitates serious medical attention.

On studying work-related factors in the current study, inappropriate office equipment, low decision authority and task complexity were significantly associated with neck complaints. A computer OW who performed complex tasks was 16.9 more likely to have neck complaints compared with OW who performed simple tasks. Moreover, computer OWs who work in an inappropriate office equipment were 6.4 times more likely to have neck complaints compared with those who had appropriate office equipment. In addition, there is $90 \%$ decreased likelihood of neck complaints among computer $\mathrm{OW}$ with high decision authority. Findings of the present study are consistent with other studies where inappropriate work station [3] and task difficulty were significant predictors of neck complaints $[3,13,24,31]$. Moreover, low decision latitude was reported as a significant predictor [3] and suggested as a risk factor for upper extremity musculoskeletal disorders in a systematic review [19].

Furthermore, in the current study, awkward body posture was significantly associated with arm/hand complaints. A computer OW who used to sit in awkward body posture at work was 6.2 times more likely to have arm/hand complaints compared with OW who used to sit in a comfortable position. Similarly, Ranasinghe et al. [3], found that improper body posture was a significant predictor for arm/hand complaints. Remaining seated for long periods at work increases pressure on joints, stresses ligaments and provokes muscle pain [32].

Regarding the association between CANS and break time, in the current study, there was $90 \%$ decreased likelihood of arm/hand complaints among computer OWs who had high-quality break. In addition, high level of break autonomy was significantly associated with neck and arm/ hand complaints. According to the results of the present study, a computer OW with high level of break autonomy was 2.6 times more likely to have neck complaints and 3.2 times more likely to have arm/hand complaints compared with OW who had low level of break autonomy. Participants in the current research were recruited mainly from private companies where break time is a standard part of the work day. Effectiveness of break time depends on the activity practiced during break such as doing relaxation activities, socializing, or working. Research showed that employees were less fatigued at the end of the day if they had relaxation activities, and more fatigued if they had worked or had social activities during break [33]. Having higher levels of break autonomy does not necessarily mean higher levels of useful relaxation activities. In other words, break time may offer little opportunity for relaxation and greater chance to activities that heighten exhaustion and provoke complaints.

\section{Limitations of the study}

Measurement of the ergonomic hazard at workplace was subjective. Actual measurements using, for example, the validated Occupational Safety and Health Administration workstation checklist [34] would give more accurate results. The present study was cross-sectional; however, a prospective cohort study would be better as it has no recall bias and can accurately determine cause-effect relationship. 


\section{CONCLUSION AND RECOMMENDATIONS}

High prevalence of CANS among computer OWs was reported. Most complaints were mild. Multiple factors in the three main categories (demographic, physical and psychosocial) were involved in occurrence of CANS. The (small) differences in relative importance of different factors, reported also in different studies, might relate to particulars of working population in different countries. Therefore, it is recommended to design preventive strategies according to the significant modifiable factors identified for each specific working population. Prospective cohort studies that accurately examine risk factors for CANS are required in future research.

\section{ACKNOWLEDGEMENTS}

The author appreciates cooperation of computer OWs who participated in the study.

\section{Conflicts of interest}

Author declares that there is no conflict of interest.

\section{REFERENCES}

1. Huisstede BM, Miedema HS, Verhagen AP, Koes BW, Verhaar JA. Multidisciplinary consensus on the terminology and classification of complaints of the arm, neck and/or shoulder. Occup Environ Med 2007; 64:313-319.

2. Bekiari EI, Lyrakos GN, Damigos D, Mavreas V, Chanopoulos K, Dimoliatis ID. A validation study and psychometrical evaluation of the Maastricht Upper Extremity Questionnaire (MUEQ) for the Greekspeaking population. J Musculoskelet Neuronal Interact $2011 ; 11: 52-76$

3. Ranasinghe P, Perera YS, Lamabadusuriya DA, Kulatunga S, Jayawardana N, Rajapakse S, et al. Work related complaints of neck, shoulder and arm among computer office workers: a cross sectional evaluation of prevalence and risk factors in a developing country. Environ Health 2011; 10:70.

4. Computer Workstation. OccupSaf Heal. United States Department of Labour; 2012. [Accessed 2017 Feb 22]. Available at: http://www.OSHA.gov.

5. Eltayeb SM, Staal JB, Hassan AA, Awad SS, de Bie RA. Complaints of the arm, neck and shoulder among computer office workers in Sudan: a prevalence study with validation of an Arabic risk factors questionnaire. Environ Health 2008; 7:33.

6. Andersen JH, Fallentin N, Thomsen JF, Mikkelsen S. Risk factors for neck and upper extremity disorders among computers users and the effect of interventions: an overview of systematic reviews. PLoS One 2011; 6:e19691.

7. Eltayeb S, Staal JB, Kennes J, Lamberts PH, de Bie RA. Prevalence of complaints of arm, neck and shoulder among computer office workers and psychometric evaluation of a risk factor questionnaire. BMC Musculoskelet Disord 2007; 8:68.

8. Faryza E, Murad MS, Anwar S. A study of work related complaints of arm, neck and shoulder (CANS) among office workers in Selangor and Kuala Lumpur. Malaysian J Public Health Med 2015; 15:8-16.

9. Singh V, Goyal N, Singh A, Bhatty SM, Deane A, Prakash JS. Upper limb musculoskeletal disorders associated with computer usage in health-care professionals. Int J Med Sci Public Health 2015; 4:1615-1619.

10. Klussmann A, Gebhardt H, Liebers F, Rieger MA Musculoskeletal symptoms of the upper extremities and the neck: a cross-sectional study on prevalence and symptom-predicting factors at visual display terminal (VDT) workstations. BMC Musculoskelet Disord 2008; 9:96.

11. Scott PA. Ergonomics in developing regions needs and applications. New York, NY: Taylor \& Francis Group; 2009

12. Prodanovska-Stojcevska V, Jovanovic J, Jovanovska $\mathrm{T}$. Body posture in relation with musculoskeletal symptoms amongst computer operators. $\mathrm{Br} \mathrm{J}$ Med Med Res 2015; 7:203-210.

13. Eltayeb S, Staal BJ, Hassan A, de Bie RA. Work related risk factors for neck, shoulder and arms complaints: a cohort study among dutch computer office workers. J Occup Rehabil 2009; 19:315-322.

14. Shabbir M, Rashid S, Umar B, Ahmad A, Ehsan S. Frequency of neck and shoulder pain and use of adjustable computer workstation among bankers. Pak J Med Sci 2016; 32:423-426.

15. Habibi E, Asaadi Z, Khobi J, Barkhordari A, Zarei $\mathrm{KF}$, Karchani $\mathrm{M}$, et al. Investigation of upper limb disorders and its relationship with physical working requirements among metallic industry workers. Electron Physician 2012; 4:506-510.

16. Gerr F, Monteilh CP, Marcus M. Keyboard use and musculoskeletal outcomes among computer users. J Occup Rehabil 2006; 16:265-277.

17. IJmker S, Huysmans MA, Blatter BM, Beek AJ, Mechelen W, Bongers PM. Should office workers spend fewer hours at their computer? a systematic review of the literature. Occup Environ Med 2007; 64:211-222.

18. Andersen JH, Harhoff M, Grimstrup S, Vilstrup I, Lassen CF, Brandt LP, et al. Computer mouse use predicts acute pain but not prolonged or chronic pain in the neck and shoulder. Occup Environ Med 2008; 65:126-131. 
19. Bongers PM, Kremer AM, terLaak J. Are psychosocial factors, risk factors for symptoms and signs of the shoulder, elbow, or hand/wrist? a review of the epidemiological literature. Am J Ind Med 2002; 41:315-342.

20. Van den Heuvel SG, van der Beek AJ, Blatter BM, Hoogendoorn WE, Bongers PM. Psychosocial work characteristics in relation to neck and upper limb symptoms. Pain 2005; 114:47-53.

21. Csorny L. Careers in the growing field of information technology services. Beyond the Numbers: Employment \& Unemployment, vol. 2, no. 9 (U.S. Bureau of Labor Statistics, April 2013), [cited 2017 July 12] Available at URL: https:/www.bls.gov/ opub/btn/volume-2/careers-in-growing-field-ofinformation-technology-services.htm.

22. Adedoyin RA, Idowu BO, Adagunodo RE, Owoyomi AA, Idowu PA. Musculoskeletal pain associated with the use of computer systems in Nigeria. Technol Health Care 2005; 13:125-130.

23. Karasek R, Brisson C, Kawakami N, Houtman I, Bongers P, Amick B. The Job Content Questionnaire (JCQ): an instrument for internationally comparative assessments of psychosocial job characteristics. J Occup Health Psychol 1998; 3:322-355.

24. Hannan LM, Monteilh CP, Gerr F, Kleinbaum DG, Marcus M. Job strain and risk of musculoskeletal symptoms among a prospective cohort of occupational computer users. Scand J Work Environ Health 2005; 31:375-386.

25. Darmawan J. Recommendations from the Community Oriented Program for Control of Rheumatic Disease for data collection for the measurement and monitoring of health in developing countries. Clin Rheumatol $2007 ; 26: 853-857$.

26. Habib RR, Hamdan M, Nuwayhid I, Odaymat F, Campbell OM. Musculoskeletal disorders among full-time homemakers in poor communities. Women Health 2005; 42:1-14.
27. Al Wazzan KA, Almas K, Al Shethri SE, Al-Qahtani MQ. Back \& neck problems among dentists and dental auxiliaries. J Contemp Dent Pract 2001; 2:17-30.

28. Gerr F, Marcus M, Ensor C, Kleinbaum D, Cohen S, Edwards A, et al. A prospective study of computer users: I. Study design and incidence of musculoskeletal symptoms and disorders. Am J Ind Med 2002; 41:221235.

29. Hooftman WE, Beek AJ van der, Bongers PM, van Mechelen W. Gender differences in self-reported physical and psychosocial exposures in jobs with both female and male workers. J Occup Environ Med 2005; 47:244-252.

30. Kryger AI, Andersen JH, Lassen CF, Brandt LP, Vilstrup I, Overgaard E, et al. Does computer use pose an occupational hazard for forearm pain; from the NUDATA study. Occup Environ Med 2003; 60:e14.

31. Ariens GA, Bongers PM, Hoogendoorn WE, van der Wal G, van Mechelen W. High physical and psychosocial load at work and sickness absence due to neck pain. Scand J Work Environ Health 2002; 28:222-231.

32. Ortiz-Hernandez L, Tamez-Gonzalez S, MartinezAlcantara S, Mendez-Ramirez I. Computer use increases the risk of musculoskeletal disorders among newspaper office workers. Arch Med Res 2003; 34:331-342.

33. Trougakos J, Hideg I, Cheng B, Beal D. Lunch Breaks Unpacked: The role of autonomy as a moderator of recovery during lunch. Acad Manage J 2014; 57:405421.

34. Occupational Health and Safety Administration (OSHA). Computer Workstation eTool: 2016. [cited 2017 Feb 11). Available at: http://www.osha.gov/ SLTC/etools/computerworkstations/index.html. 